\title{
pnmbalina
}

(8)

Papéis e desafios para a intervenção em serviço social: o caso das empresas sociais na Suíça
Autor(es):
Pinho, Jorge
Publicado por: Imprensa da Universidade de Coimbra
URL
persistente:
URI:http://hdl.handle.net/10316.2/29879
DOI:
DOI:http://dx.doi.org/10.14195/978-989-26-0769-6_6
Accessed : $\quad$ 26-Apr-2023 10:40:16

A navegação consulta e descarregamento dos títulos inseridos nas Bibliotecas Digitais UC Digitalis, UC Pombalina e UC Impactum, pressupõem a aceitação plena e sem reservas dos Termos e Condições de Uso destas Bibliotecas Digitais, disponíveis em https://digitalis.uc.pt/pt-pt/termos.

Conforme exposto nos referidos Termos e Condições de Uso, o descarregamento de títulos de acesso restrito requer uma licença válida de autorização devendo o utilizador aceder ao(s) documento(s) a partir de um endereço de IP da instituição detentora da supramencionada licença.

Ao utilizador é apenas permitido o descarregamento para uso pessoal, pelo que o emprego do(s) título(s) descarregado(s) para outro fim, designadamente comercial, carece de autorização do respetivo autor ou editor da obra.

Na medida em que todas as obras da UC Digitalis se encontram protegidas pelo Código do Direito de Autor e Direitos Conexos e demais legislação aplicável, toda a cópia, parcial ou total, deste documento, nos casos em que é legalmente admitida, deverá conter ou fazer-se acompanhar por este aviso.

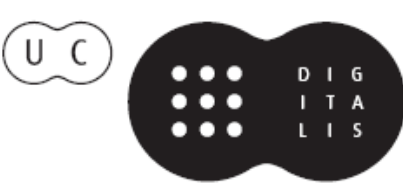




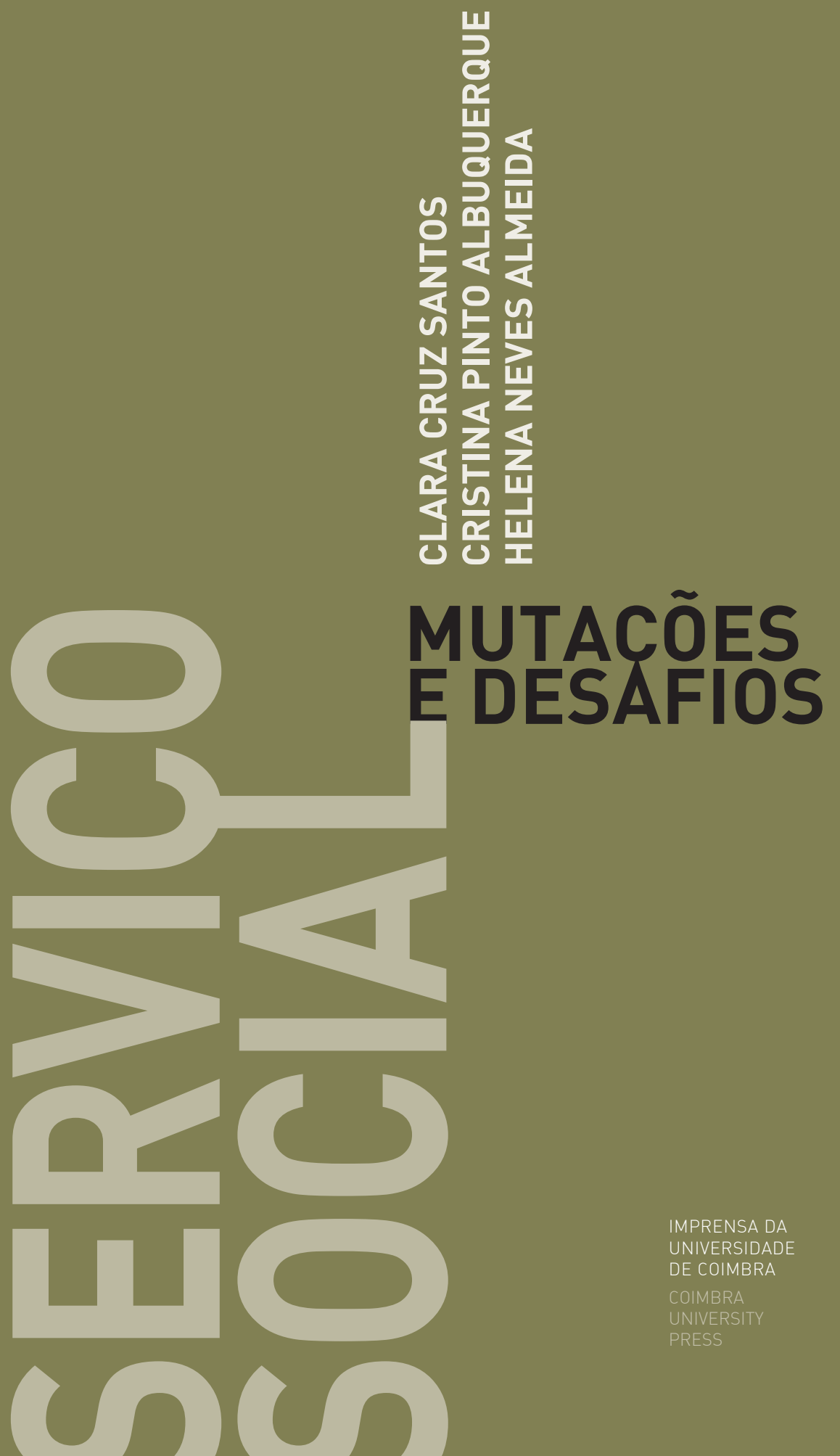


Jorge Pinho

Véronique Antonin-Tattini

\section{CAPITULO VI \\ PAPÉS E DESAFIOS PARA A INTERVENÇÃo \\ EM SERVIÇO SOCIAL: O CASO DAS \\ EMPRESAS SOCIAIS NA SUÍÇA ${ }^{18}$}

\section{Introdução}

Inscrevendo-se num movimento generalizado de desenvolvimento dos dispositivos ativos do Estado ligado ao paradigma de inserção, objeto ele próprio de diversas organizações e práticas profissionais, as empresas sociais aparecem e evoluem na Suíça com diversos enquadramentos das políticas sociais. Estruturas híbridas, tanto do ponto de vista dos públicos acolhidos em inserção como dos seus modos de financiamento, estas empresas não são consensuais no que diz respeito à sua definição.

Após recordar a passagem do Estado Providência a um Estado Social ativo, tentaremos compreender os respetivos impactes sobre as práticas profissionais do Trabalho Social ${ }^{19}$. De seguida, aprofundaremos a definição e a intervenção das empresas sociais, nomeadamente na Suíça francófona, neste contexto de mutações. Esta fundamentação permitirá apreender e entender o interesse suscitado por estas estruturas. Deste modo, poderemos finalmente questionar e compreender a implicação do Trabalho Social na ligação com as

18 Tradução do francês efetuada por Cristina Albuquerque.

19 Optou-se neste capítulo pela manutenção da designação de "trabalho social" (travail social) por se encontrar mais em consonância com a realidade Suíça, que enquadra, neste conceito, profissões e ocupações diferenciadas entre as quais a de Serviço Social (n.d.t). 
empresas sociais, identificando ao mesmo tempo novas oportunidades, mas também novos desafios a enfrentar.

\section{Contextualização das mutações}

\subsection{Do Estado Providência ao Estado Social ativo}

A ideia de que o Estado-Providência construído durante os "trinta anos gloriosos" - um Estado-Providência paternalista, intervencionista e protetor evoluiu bastante após a década de 70 do século XX é hoje largamente aceite. Rosanvallon (1981) evoca mesmo a situação de crise desse modelo estatal na sua obra, publicada em 1981, e intitulada precisamente La Crise de l'Etat Providence. Na mesma linha de pensamento, Chopart (cit. in Soulet, 1997) resume a crise do Estado Providência identificando três eixos críticos: uma crise de "legitimidade", uma crise "financeira" e, finalmente, uma crise da "ação pública”.

"A desagregação da sociedade salarial" (Castel, 2009) sobre a qual assentava a organização da proteção social exige de facto que esta seja repensada. Neste contexto de crise do Estado-Providência observamos que o mesmo desliza progressivamente para um modelo de Estado social ativo ou incentivador. Com efeito, o Estado social "busca um novo modo de governabilidade em torno do que poderíamos apelidar um "Estado Social ativo» que corresponde à exigência colocada ao poder público de responder aos desafios da situação atual" (Castel, 2009, p. 215).

Neste contexto, numa conceção em que "o Estado Social se transformou em Estado da "ativação" do indivíduo em dificuldade" (Soulet, 2008, p. 1), os mecanismos de contraprestação, inspirados no workfare, assumem um lugar central, articulando o direito às prestações sociais com uma exigência de contrapartida: o cidadão, incluindo aquele que recebe prestações sociais, tem certamente direitos, mas tem também, e sobretudo, deveres, sob a forma de prescrições comportamentais, como por exemplo os esforços desenvolvidos e demonstrados para retomar o mercado de emprego. De uma forma geral a execução deste referencial do Estado Social ativo centra-se não somente sobre 
uma implicação e ativação do indivíduo, mas também sobre uma individualização, territorialização e contratualização das suas intervenções (Badan, Bonvin \& Moachon, 2004).

A individualização relaciona-se com o facto da ação pública se centrar em primeiro lugar sobre o indivíduo e a sua singularidade (Cantelli \& Genard, 2007). As políticas sociais são um dos domínios onde encontramos particularmente esta visão. Assim, as prestações estandardizadas das políticas sociais convencionais, baseadas sobre riscos sociais identificados e predefinidos, tendem a ser substituídas por "abordagens talhadas à medida" (Badan, Bonvin \& Moachon, 2004, p. 382).

A territorialização decorre dos mecanismos de ativação e de individualização. Trata-se de inscrever no território local, na proximidade, a ação pública em matéria de políticas sociais, o que se traduz por uma maior margem de manobra proporcionada aos atores locais (Badan, Bonvin \& Moachon, 2004).

Finalmente, a contratualização desenvolve-se não somente nas relações entre o Estado e os organismos de aplicação de prestações sociais, mas diz também respeito às ajudas concedidas aos beneficiários. Como mostra Supiot (2002) assistimos, nos anos 90, ao que ele apelida de "refeudalização" da sociedade, na medida em que a prática do contrato tem tendência a preceder a lei, como se, ao longo do tempo, o "elo contratual [se tivesse tornado] a forma mais acabada do elo social" (Supiot, 2002, p. 155).

Estas práticas não deixam de colocar, no entanto, um certo número de questões, entre as quais a das relações de poder, mais ou menos implícitas, induzidas pelo contrato, ou a da igualdade entre as partes contratantes. A propósito do poder exercido pelo trabalho social neste tipo de práticas, Castel (1995, p. 471) salienta que "é então o interventor social que é juiz da legitimidade do que se constitui como contrato e que concede ou não a prestação financeira em função desta avaliação. Exerce uma verdadeira magistratura moral”. Supiot (2002) lembra, por seu turno, que estes contratos, embora impostos por lei, não ligam jamais partes iguais e que "o utente se transforma [então] em contraente obrigado" (Supiot, 2002, p. 155).

Estas evoluções não acontecem, pois, sem um certo número de ambiguidades e de efeitos perversos (Soulet, 1999; Castel, 2009), tais como a 
sobrerresponsabilização e a moralização acrescida dos beneficiários, os tratamentos arbitrários e desiguais das pessoas em dificuldade, ou ainda, a mercantilização da ação social (dar para receber).

Neste contexto, evoquemos ainda brevemente o paradigma da inserção, já que o Estado Social dito "ativo" coloca no âmago dos seus objetivos e das suas preocupações a questão da inserção socioprofissional: ativar para inserir.

A noção de inserção é uma "palavra fortemente polissémica servindo para designar o acesso ao mercado de trabalho e a integração social de populações específicas, nomeadamente os jovens que abandonam a escola" (Dubar citado por Guichard \& Huteau, 2007, p. 257). A problemática da inserção desenvolve-se assim no quadro das mutações do trabalho, e mais precisamente do emprego, e das funções que este deveria assegurar, mesmo que já não o consiga excluindo desse modo uma parte da população.

A inserção e as políticas que com ela se relacionam são consideradas desde logo como uma resposta indispensável a estas "desregulações", na medida em que concretizam dispositivos específicos e individualizados colocados em marcha pelas políticas públicas com o objetivo de religar o maior número de pessoas. Por outro lado, a inserção descreve tanto um processo dinâmico, uma passagem de uma situação para outra comportando diversas etapas, como um estado estabilizado no qual o indivíduo estaria plena e definitivamente inserido, participando "na vida da cidade, e muito em particular no plano dos papéis económicos (produção e consumo) e sociais, e até médico-sociais (habitação, saúde, cidadania)" (Castra, 2003, p. 10). Uma outra questão alvo de discussão relaciona-se com a distinção entre inserção social e inserção profissional. Para alguns, a primeira seria uma condição prévia sine qua non para a segunda, enquanto para outros, uma inserção social completa só seria possível por via da inserção profissional.

Em qualquer dos casos, a noção de inserção induz o desenvolvimento de um certo número de práticas profissionais focalizadas no acompanhamento das diferentes etapas do processo evocado. Práticas profissionais que emergem, nomeadamente, sob o impulso do trabalho social, como tentaremos mostrar no ponto seguinte. 


\subsection{Que implicações para as práticas de trabalho social?}

Coloca-se agora a questão da ligação entre, por um lado, as transformações do Estado Social e, por outro, a questão da inserção socioprofissional efetivada pelos trabalhadores sociais. Dito de outro modo, em que medida o trabalho social é influenciado pelas evoluções descritas anteriormente?

A resposta deve ser procurada numa outra dinâmica evolutiva, a do próprio trabalho social. Com efeito, a execução das políticas e dos dispositivos de inserção foi conduzida em grande parte pelo trabalho social e pelas suas mutações recentes. Para Chopart (2000) a emergência de uma nova questão social - desemprego em massa e de longa duração, mutação e precarização do emprego, fenómenos de precariedade e de exclusão em larga escala, etc - é uma das origens, para não dizer a origem, das "mutações do trabalho social". Estas mutações traduzem-se, entre outros aspetos, por uma "complexificação crescente dos dispositivos de ação social”, bem como pelo enfraquecimento de "identidade profissional dos trabalhadores sociais" (Chopart, 2000, p. 2-3). Também Autès (2004, pp. 153-157) destaca bem os elos que se criam entre inserção, ação social e trabalho social:

A pobreza, depois a exclusão, tornam-se novos modos de problematização da questão social. Ao mesmo tempo, uma nova categoria de ação social toma forma com as diferentes estratégias de intervenção que se reagrupam sob a noção de inserção. (...) A categoria de inserção nasceu nas fronteiras do social. Penetrou-as de seguida para alterar profundamente as suas lógicas internas. Os trabalhadores sociais participaram plenamente na emergência deste novo referencial de ação e das suas novas maneiras de fazer. Podemos mesmo dizer que eles são, de alguma forma, senão sempre, os inventores, pelo menos os experimentadores.

Entre as evoluções que se operam no âmbito da intervenção e das práticas profissionais, três parecem ser de destacar como particularmente pertinentes para os propósitos que pretendemos: primeiro a emergência de novas ocupações no campo social; de seguida, o crédito acrescido dado às competências em detrimento da qualificação e, por fim, a cristalização das práticas 
profissionais em torno da ferramenta de projeto, e em particular do projeto de inserção, concretizando a orientação para a individualização e para a ativação.

Desde logo, o desenvolvimento de dispositivos de intervenção no campo da inserção é "propício" às transformações das ocupações clássicas do social, bem como ao aparecimento de novas. Como evidencia Vrancken (2010, p. 43),

Esta propensão à particularização das intervenções e à definição de novas categorias de beneficiários traduz-se no aparecimento de novas ocupações de serviços às pessoas ou de "trabalhadores sobre o outro": ao lado dos trabalhadores sociais, dos psicólogos, dos médicos, vêm juntar-se os mediadores, os avaliadores, os conselheiros, os agentes de inserção ${ }^{20}$, os agentes de acolhimento, os coachers, os gestores de caso, os gestores de projeto, os assistentes de justiça, os acompanhadores, pedagogos, conselheiros e formadores de todas as margens.

Em paralelo, a noção de “intervenção social” tende a suplantar a de "trabalho social" propriamente dito, precisamente para traduzir o alargamento que se produz simultaneamente nas profissões do social. Novos ofícios do social aparecem (...) cujo perfil é muito diferente do dos trabalhadores sociais clássicos»(Castel, 2009, p. 237). Dito de outro modo, os interventores sociais podem ser trabalhadores sociais, mas não só. São profissionais que se congregam em torno de práticas comuns: o acento colocado sobre a intervenção com o indivíduo precarizado ${ }^{21}$, sobre a sua trajetória de vida, sobre os défices pessoais que o impedem de ser ativo e de apanhar o comboio em marcha, o da inserção.

A evolução dos ofícios do social evidencia, de seguida, a questão da qualificação dos trabalhadores sociais, colocada à prova pelas novas problemáticas existentes. Neste contexto, a lógica da qualificação, assentando sobre a formação,

\footnotetext{
20 No original "placeurs" (n.d.t.).

21 O tratamento da precariedade não está isento de paradoxos para o trabalho social: enquanto a "precariedade é um risco social que afeta populações diferentes daquelas que sofrem de um défice pessoal»(Castel, 2009, p. 234), a intervenção social continua focalizada sobre o indivíduo.
} 
tende a ser substituída pela da expertise, fundando-se sobre competências profissionais. Contrariamente à qualificação, entendida como algo de estáti$\mathrm{co}$, de (ultra) passado e, consequentemente, de inadaptado às necessidades reais e concretas dos utentes, a competência permitiria responder melhor a estes desafios. Dinâmica, flexível e adaptativa ela reforçaria o crédito e a pertinência das respostas construídas para os problemas identificados. A competência estaria, em definitivo, mais próxima das realidades do terreno. A competência parece assim questionar a qualificação profissional no que respeita à "relação social entre, por um lado, o mundo da formação, o dos diplomas, da hierarquia dos valores do ensino e, por outro, o mundo do trabalho e da determinação das classificações e dos salários" (Dubar citado por Chauvière \& Tronche, 2002, p. 77). Como se o diploma não bastasse para atestar uma expertise, devendo esta ser reconhecida e confirmada em situação real, ou seja, pelos empregadores ${ }^{22}$ e não pelas instituições de ensino. Passamos assim de uma "lógica estatutária da qualificação (...) para uma lógica gestionária da competência, na qual o diploma, estatuto e posto estão dissociados em proveito de uma consideração principal das competências individuais" (Bertaux citado por Chauvière \& Tronche, 2002, p. 77).

Nesta ótica compreendemos melhor, desde logo, que novos perfis de profissionais, reconhecidos como competentes e experts graças a aptidões próprias, entrem no campo social, ao lado dos trabalhadores sociais clássicos, como destaca aliás Bertaux (citado por Chauvière \& Tronche, 2002, pp. 80-81),

Os responsáveis hesitam em contratar trabalhadores sociais históricos, preferem titulares de outras qualificações (universitárias, artesanais, industriais, comerciais, bancárias...), mas sobretudo refletem sobre os critérios de contratação menos a partir da qualificação (diplomas) do que a partir das competências individuais das pessoas, ponderadas em particular através das suas trajetórias profissionais (o curriculum vitae).

\footnotetext{
22 Yvon Cannac, citado por Dubar, define a competência como sendo precisamente "o que se manifesta no trabalho e o que é reconhecido pelo empregador. (...) Atenção, é a empresa que reconhece a competência e que a remunera" (Cannac citado por Dubar, em Chauvière \& Tronche, 2002, p. 77).
} 
Uma referência por fim à cristalização das práticas profissionais em torno da dinâmica de projeto e mais especificamente do projeto de inserção contratualizado, enquanto mudança que se opera no quadro da intervenção social. O utente não pode mais, no contexto descrito precedentemente, contentar-se com uma atitude passiva. Pelo contrário, espera-se dele que, apesar das suas dificuldades, seja capaz de se projetar no futuro e de construir mesmo um projeto profissional individualizado, fazendo tudo o que lhe é possível para o realizar ${ }^{23}$. O projeto seria o "instrumento ad hoc" para assegurar a participação ativa do utente e permitir-lhe desse modo "tornar-se ele próprio" (Boltanski \& Chiapello citados por Astier, 2007, p. 118). O envolvimento esperado por parte do utente é de seguida formalizado e consignado num contrato ligando-o ao interventor social; contrato que estipula, entre outros aspetos, as partes contraentes, os objetivos visados, as etapas esperadas, os critérios e modalidades de avaliação, etc.

"Responsabilidade», "envolvimento» e "implicação» dizem respeito não apenas ao utente mas também ao trabalhador social enquanto representante da "comunidade". "Esta cultura do projeto assinala a emergência de uma nova normatividade assentando sobre a ação, enaltecendo a implicação de cada um" (Astier, 2007, p. 118). Utilizando instrumentos diversos tais como o contrato, os objetivos específicos ou ainda os balanços, o trabalhador social ativo no campo da inserção socioprofissional, assume a corresponsabilidade do processo em questão. O profissional da inserção torna-se assim uma espécie de gestor de percursos individuais (Ion, 1999, 2006; Chopart, 2000; Vrancken \& Thomsin, 2008). Torna-se também o "companheiro" dos utentes nos seus percursos de inserção, feitos de sucessos e fracassos, reconhecendo em simultâneo as suas necessidades e reforçando os seus recursos. "Trata-se de "fazer fazer» e não mais de pensar «em vez de»" (Astier, 2007, p. 118).

Em definitivo, as transformações recentes das lógicas de ação e de intervenção do trabalho social e a emergência de um Estado Social ativo - assentando

\footnotetext{
23 A lógica de projeto não deixa de ter efeitos "perversos». Por exemplo, vários autores destacam a possível sobrerresponsabilização dos indivíduos face à sua situação, que, em caso de falhanço, pode reforçar a impressão de incapacidade ("não sou capaz de") e transformar-se em sentimento de culpabilidade ("é culpa minha").
} 
sobre os mecanismos de individualização, de territorialização e de contratualização - surgem pois como evoluções paralelas (Castel, 2009). As empresas sociais de inserção inscrevem-se precisamente neste contexto de mutações, como iremos ver no ponto que se segue.

\section{As Empresas Sociais na Suíça}

Na Suíça, como em outros países, a noção de inserção inscreve-se não somente nas diversas políticas sociais de luta contra a pobreza e a exclusão, mas torna-se também o objeto de práticas profissionais e de toda uma panóplia de organizações e de instituições, oferecendo nomeadamente atividades de formação, de orientação profissional ou ainda de inserção pelo económico tendo em vista esta finalidade. Entre estas organizações, as empresas sociais, como forma específica de empresa, estão cada vez mais em voga também no contexto helvético, particularmente nos discursos políticos e nas práticas de terreno em matéria de inserção.

Esta agitação em torno das empresas sociais está em grande parte ligada à orientação das políticas sociais em matéria de reinserção profissional (Bonoli, 2008) ${ }^{24}$, isto num contexto de restrições das despesas públicas e de externalização de missões dos serviços públicos para uma multiplicidade de atores privados. Por outro lado, esta efervescência está também em consonância com a emergência de uma nova antropologia das capacidades e competências, em ligação com um Estado social ativo, referindo-se particularmente aos beneficiários precarizados e, de forma geral, aos cidadãos, intimados a agir e a serem ativos num contexto complexo (Cantelli \& Genard, 2007). Capacidades e competências que são aliás pensadas como elementos prévios necessários à reinserção no mercado de trabalho e que se encontram doravante, como já salientámos, no âmago da profissionalização em trabalho social.

\footnotetext{
24 À semelhança da introdução das recomendações da Conferência Suíça das Instituições de Ação Social (CSIAS) que incitam os serviços de ajuda social dos cantões e das comunas helvéticas a oferecer novas possibilidades de inserção (Tecklenburg, 2006).
} 


\subsection{Definição das empresas sociais na Suíça}

Neste contexto as denominações e definições das empresas sociais não são uniformes. Considerando que o conceito de empresa social enquadra designações, e ainda estatutos jurídicos variados (do estatuto associativo ao das categorias de natureza comercial), segundo os países e mesmo no seio de um mesmo contexto nacional, a grande parte dos trabalhos internacionais (OCDE e EMES ${ }^{25}$ ) preocupou-se em definir previamente este termo (Antonin-Tattini \& Bruttin-Troutot, 2009, p. 121).

No que diz respeito à Suíça, diversas denominações são igualmente utilizadas para designar as empresas sociais, desde empresa social de inserção pelo económico, a atelier para pessoas deficientes, passando pela noção de programa de emprego temporário. Em definitivo, aqui e em outros locais, o conceito de empresa social representa uma síntese das diversas denominações associadas a estas iniciativas. Todavia, ainda que as organizações que se reconhecem nesta noção de empresa social se multipliquem, e até se autorrotulem, elas não se constituem como um dispositivo definido e explicitado nas políticas públicas existentes ou nos quadros legais que seriam específicos para este tipo de empresa. Isto, contrariamente a outros países, como por exemplo o Canadá, onde o governo do Québéc adotou, em 1998, um quadro legal de reconhecimento do papel das empresas de inserção e do seu financiamento, tendo por base critérios de definição que permitem qualificar o que é uma empresa social.

No momento, as definições das empresas sociais na Suíça são elaboradas por diversas iniciativas locais, nomeadamente, a Comunidade Suíça de Trabalho das Empresas Sociais (Communauté Suisse de Travail des Entreprises Sociales, ASSOF ${ }^{26}$ ), o Conselho Românico de Inserção pelo Económico (Conseil Romand de l'Insertion par l'Économique, CRIEC), ou iniciativas de cidades e de organizações do mundo associativo. Estas diversas iniciativas

25 A EMES é uma rede de investigadores de vários países e as iniciais significam «Emergência das Empresas Sociais na Europa".

26 A Comunidade Suíça de Trabalho das Empresas Sociais (ASSOF) envolve-se na identificação, aceitação e difusão de firmas sociais como uma das formas de empresa na Suíça (Adam, 2010, p. 7). 
não partilham todas os mesmos critérios para a definição de uma empresa social. Deste modo, decorrendo destas imprecisões concetuais, este tipo de empresa é difícil de distinguir dos outros tipos de organizações no domínio da inserção. Sem esquecer que a definição de uma empresa social continua a ser uma questão política na promoção e sustentação de tais estruturas. Colocando uma fronteira entre as organizações que se situam dentro e fora desta definição, identificamos os efeitos desta indefinição no que diz respeito à possibilidade nomeadamente de ter acesso a fundos públicos, a informações ou a redes. Por outro lado, é claro que o número de empresas sociais referenciadas está dependente da definição considerada. Logo, na ausência de definição consensual para o caso suíço, este número é desconhecido; as hipóteses oscilam entre 60 e 300 (Adam, 2010, p. 6).

Para além destas denominações e imprecisões concetuais, e ainda que as empresas sociais tenham especificidades variáveis segundo os países e os contextos, de acordo com as definições admitidas na Europa uma empresa social de inserção tem como finalidade o enquadramento das pessoas excluídas no mercado de trabalho, através da produção e venda de bens e serviços para um mercado (ou seja, proporcionar um "verdadeiro" trabalho), com um risco económico significativo ${ }^{27}$ (Dunand, 2010, p. 148). Salienta-se pois que os trabalhos de pesquisa europeus desenvolveram critérios de definição de uma empresa social que não assentam sobre os seus estatutos jurídicos, os seus modos de financiamento ou as suas atividades económicas ${ }^{28}$.

Para simplificar, podemos afirmar que as empresas sociais se assemelham pela combinação de objetivos económicos e sociais, próprios deste tipo de

27 O grau de risco económico de uma empresa social está associado sobretudo à proporção das receitas recebidas pela venda de bens e serviços num mercado por referência às receitas totais que detém. O critério de produção de bens e serviços para um mercado permite diferenciar as empresas sociais dos ateliers protegidos que se focalizam em trabalhos ocupacionais ou terapêuticos.

28 Os domínios de atividades das empresas sociais de inserção na Suíça parecem próximos do que podemos observar em outros países: restauração, jardinagem, limpezas, funções de portaria (arrecadação, despejo, entregas), acabamentos da construção, reciclagem de vestuário, de computadores, de mobiliário e outros, sub-tratamentos para a indústria, marcenaria, serralharia, etc. (Dunand \& Dupasquier, 2006). Estas atividades, que devem estar acessíveis para os beneficiários pouco ou não qualificados, ou tendo outras dificuldades, são geralmente pouco rentáveis, tanto na Suíça como fora do país, o que limita a taxa de autofinanciamento das empresas sociais e a sua independência dos financiadores. 
iniciativas, em que as ferramentas económicas estão ao serviço do social. Ainda assim, o equilíbrio entre estas duas dimensões nem sempre é fácil de assegurar. Com efeito, se os constrangimentos económicos de uma empresa social, inerentes a uma verdadeira firma, são prioritários por referência aos fins sociais, ela encontra-se então face a um risco de instrumentalização e exploração dos seus beneficiários, isto em detrimento do acompanhamento necessário à sua reinserção (Antonin-Tattini \& Bruttin-Troutot, 2009, p. 124). Por outro lado, se os objetivos sociais pesam mais na balança, a empresa social encontra-se confrontada com um risco de perda de mercados e de institucionalização da exclusão, não desempenhando deste modo o papel de ponte com o mercado de emprego, com o risco, para os beneficiários, de não sairem do circuito da reinserção.

\subsection{A diversidade das empresas sociais helvéticas}

As diversas denominações e definições utilizadas a propósito das empresas sociais tendem a reforçar a sua diversidade no contexto helvético, nomeadamente na Suíça francófona, não sendo possível identificar uma empresa social tipo.

Neste contexto, as empresas sociais são muitas vezes apresentadas como inovações recentes. No entanto, muitas não o são. Constituem antes uma evolução nas formas de responder à necessidade de trabalhar das pessoas excluídas do mercado principal de emprego, quer sejam categorizadas como desempregadas, inválidas ou outros (Dunand, 2010).

$\mathrm{Na}$ realidade, três correntes históricas conduziram à diversidade de empresas sociais que encontramos atualmente na Suíça. A primeira categoria corresponde aos ateliers protegidos para pessoas deficientes, criados por volta dos anos 50 (Dunand, 2010). As novas conceções dominantes na área da deficiência, mas também a quinta revisão do subsídio de incapacidade (sustentada por toda uma produção estatística comprovando o aumento dos casos de incapacidade psíquica) contribuiram para fazer progredir o modelo de atelier ocupacional. Outras empresas sociais foram criadas, nos anos 80, sobretudo por razões associadas à diversificação dos modos de intervenção 
social com os beneficiários de ajuda social, oferecendo-lhes atividades produtivas para os reenquadrar no trabalho, tendo em vista o seu acesso ao mercado de emprego. Finalmente, a última categoria de empresas sociais emergiu nomeadamente para responder ao aumento do desemprego de longa duração. Estas, dependentes maioritariamente da legislação sobre o desemprego, que comporta uma cláusula de não concorrência com a economia privada, emergiram graças a uma interpretação pragmática destes dispositivos legais em certos cantões, bem como à indulgência dos sindicatos e do patronato (Dunand, 2010).

A estas lógicas de criação das empresas sociais sobrepõem-se, pelo menos parcialmente, diversos estatutos administrativos sob os quais são classificados os públicos excluídos do mercado de trabalho que podemos encontrar no quadro destas organizações. Com efeito, na maioria dos casos, pelo menos na Suíça francófona, as pessoas em inserção são envolvidas em circuitos sociais que são os prescritores da sua entrada em tais dispositivos e dos quais recebem em grande parte o seu rendimento de substituição (Antonin-Tattini \& Bruttin, 2009). Certas empresas sociais vão partilhar públicos em inserção decorrendo de estatutos administrativos de diversos regimes sociais (nomeadamente o subsídio de desemprego, o subsídio de incapacidade, as leis cantonais para desempregados em fim de direito, bem como leis cantonais de ajuda social). Outras empresas sociais concentram-se unicamente sobre uma categoria particular de pessoas.

Envolvendo públicos enquadrados em regimes sociais, as empresas sociais são financiadas como contrapartida das suas prestações de inserção pelos quadros legais aplicáveis, acessíveis aliás ao conjunto de organizadores de programas e medidas de inserção. Dito de outro modo, as empresas sociais são sustentadas financeiramente na sua missão de inserção, do mesmo modo que outras estruturas, e não enquanto organização com as suas especificidades e reconhecida como tal (Antonin-Tattini \& Bruttin-Troutot, 2009, p. 125). Assim, do ponto de vista das suas fontes de rendimento, ao lado de uma parte de autofinanciamento (variável segundo as empresas sociais), a maioria destas organizações é dependente de financiamentos públicos, devido nomeadamente aos seus custos de produção, mais elevados que numa empresa privada com fins lucrativos, e à contratação de públicos precários. No entanto, cada 
quadro legal possui financiamentos específicos, mas também as suas exigências (contabilistas, indicadores de eficácia, etc), nem sempre coerentes com as dos financiadores, o que complexifica a gestão quotidiana da empresa (Dunand \& Dupasquier, 2006). Por outro lado, esta dependência das legislações orientadas para a reinserção influencia não somente o tipo de financiamento público atribuído aos organizadores, mas também a remuneração ${ }^{29}$ e a duração da permanência dos públicos acolhidos no seu quadro. A este respeito, as empresas sociais dependentes de legislação associada ao desemprego e à ajuda social oferecem em maior número aos seus beneficiários, pelo menos numa grande parte da Suíça francófona, um emprego "passerelle" com duração limitada, em função das medidas de inserção limitadas no tempo das quais a maioria depende. A finalidade é que os beneficiários se reinsiram no mercado de trabalho principal. Por outro lado, as empresas sociais ligadas ao subsidio de incapacidade favorecem sobretudo empregos ocupados de forma durável por pessoas reconhecidas como incapacitadas, em particular sem perspetiva de retorno ao emprego, como é o caso dos ateliers protegidos tradicionais. De facto, para um certo número de trabalhadores, quaisquer que sejam os regimes sociais aos quais se encontram associados, uma experiência limitada de emprego numa empresa social permitir-lhes-á efetivamente recolocar-se no mercado de trabalho principal. Por outro lado, para outros, isto não basta e uma conceção da inserção como um trampolim revela-se inadequada, pelo menos a curto prazo (Dunand, 2010).

Para chegar aos assalariados das empresas sociais, segundo os modos de financiamento das suas estruturas mas também, em particular, segundo os seus objetivos prioritários, ou seja, de orientação mais económica ou mais social, os colaboradores envolvidos possuem perfis de formação distintos. As empresas sociais de orientação económica (onde predominam critérios de

29 Os modos de remuneração dos beneficiários pelas empresas sociais dependem sobretudo da margem de ação financeira permitida pelos regimes sociais dos quais os públicos envolvidos podem depender. Em certos cantões, podemos encontrar a concessão de salários parciais aos beneficiários em função do seu rendimento efetivo. A diferença para a cobertura das necessidades vitais é assumida pela ajuda social. Por outro lado, em Genève, uma tabela salarial específica subvencionada pelo Estado está em vigor para os empregos solidariedade (reconhecidos pelo dispositivo cantonal para os desempregados em fim de direito), de que fazem parte as empresas sociais. 
definição económicos) envolvem mais "técnicos" de cariz social, enquanto aquelas que são mais sociais empregam sobretudo colaboradores que são trabalhadores sociais motivados para se envolver no económico (ou mestres socioprofissionais e até monitores de ateliers) (Dunand \& Duspasquier, 2006; De Jonckeere, Mezzena \& Molnarfi, 2008).

Assim, os assistentes sociais ativos nos serviços de empresas sociais encontram-se maioritariamente neste último tipo, oferecendo não somente atividades económicas, mas também prestações psicossociais, estreitamente ligadas ao desenvolvimento das atividades quotidianas de trabalho. Esta ancoragem nas problemáticas de trabalho determina precisamente as especificidades do acompanhamento proposto pelo Serviço Social nas empresas sociais. Este acompanhamento permite agir imediatamente e "em direto" sobre as dificuldades concretas sentidas pelo beneficiário em situação real de trabalho na empresa social, facilitar a sua integração, reforçar as suas competências sociais e pessoais necessárias para esse efeito. Fazendo-o, permite também consolidar o seu percurso de inserção no mercado de trabalho principal, quando isto seja possível e realista, isto na lógica já referida de emprego "passerelle".

Para terminar, é necessário precisar que esta diversidade de empresas sociais na Suíça francófona está muito menos presente na Suíça alemã. Aqui são mais recentes, dependentes em maior número da ajuda social e associadas no momento a atividades económicas que não entram em concorrência com as empresas comerciais. Esta exigência de não concorrência conduz a duas situações, ou os gestores de empregos temporários se tornam subcontratados das empresas do mercado de trabalho, assumindo as suas necessidades de flexibilidade, ou as atividades propostas se encontram afastadas das da economia produtiva e são por esse facto pouco valorizadas pelos beneficiários.

\subsection{Os contributos das empresas sociais}

Este interesse em torno das empresas sociais faz-nos supor que elas buscam efeitos benéficos tanto ao nível macro como microssociológico. Por outro lado, explicitar a sua contribuição parece ser uma condição necessária para o seu reconhecimento político em particular, pelo menos no que concerne à Suíça. 
Diversas pesquisas, baseando-se muitas vezes sobre a literatura da economia social e solidária, têm efetivamente mostrado que este tipo de empresa traz uma contribuição positiva do ponto de vista económico, social e político, tanto para a sociedade como para os beneficiários em inserção no seu seio.

As empresas sociais inscrevem-se desde logo no quadro de uma economia plural, seguindo Laville (1994). Por exemplo, para regiões económicas, elas participam na criação de riquezas pela produção de bens e serviços para um mercado ou ainda para a criação de postos de trabalho destinados a pessoas em situação de exclusão, bem como para os colaboradores da empresa.

Por outro lado, ao nível social, as empresas sociais detêm um valor social acrescentado, nomeadamente envolvendo pessoas excluídas do mercado de trabalho tendo em vista a sua reinserção. Esta utilidade contribui para o desenvolvimento de relações de solidariedade, para a coesão social e para o aumento do capital social, o que não é negligenciável num contexto de desemprego, de exclusão e de liberalização das trocas. De facto, após uma passagem por uma empresa social, a taxa de reinserção dos beneficiários no mercado de trabalho não é descurável, pelo menos comparativamente a outros dispositivos de inserção mais ineficazes, sobretudo para aqueles que se encontram menos próximos de um emprego normal (Castra, 2003). Por exemplo, para a empresa social “Réalise”, sedeada em Genebra, em média após o ano 2000, cerca de 30\% dos estagiários encontram um emprego no mercado de trabalho principal ao longo do seu estágio ou pouco depois (Dunand, 2010, p. 148). A reinserção é muitas vezes um longo processo. Todavia, a taxa de reinserção deve ser interpretada com prudência (por exemplo, de que tipo de integração se trata?). Por outro lado, ela é apenas um indicador dos efeitos positivos do trabalho das empresas sociais. Com efeito, um percurso no seu interior contribui para um processo de aproximação dos beneficiários ao emprego: luta contra o isolamento, melhoria da saúde moral, situação familiar estabilizada, melhor nível de formação, etc., competências e capacidades que continuam dificeis de medir. A este respeito, uma pesquisa recente (De Jonckeere, Mezzena \& Molnarfi, 2008) mostra que ainda que as possibilidades de reinserção profissional no mercado continuem no fim de contas limitadas para os beneficiários das empresas sociais, há um reforço da identidade de trabalhador. 
Finalmente, as empresas sociais integram uma dimensão política. Estas, como outras instituições da economia social e solidária, integram diversas partes interessadas no seu seio e mesmo nos seus orgãos de decisão, como as assembleias gerais ou os comités. Estes públicos podem ser voluntários, assalariados, beneficiários, representantes dos poderes públicos ou ainda de empresas comerciais. Contrariamente às relações anónimas do mercado e do Estado, estes espaços democráticos permitem apreender melhor a realidade e as necessidades de inserção, bem como responder às exigências dos mercados graças à implicação dos públicos nas redes locais (Antonin-Tattini \& Bruttin-Troutot, 2009, p. 126). Todavia, no terreno, mesmo que as empresas sociais tenham a vontade de fazer participar estes diferentes públicos, a participação dos próprios beneficiários é fraca. Diversos fatores e estratégias podem travar esta vontade de participação dos públicos e nomeadamente dos beneficiários das empresas sociais.

No entanto, os contributos apresentados pelas empresas sociais não deixam de suscitar debates, nomeadamente sobre os tipos de empregos gerados por este tipo de estruturas. Uma crítica recorrente menciona o risco de criação de uma espécie de sub-mercado (considerando a fraca rentabilidade de certos nichos de atividades económicas) com a emergência de empregos precários reservados para as pessoas desfavorecidas, muitas vezes mal pagos e mal protegidos ao nível das legislações sociais.

Por outro lado, as empresas sociais propõem em geral trabalhos manuais e atividades de serviço pouco qualificadas como a reciclagem, a hotelaria, a lavandaria, etc. É preciso ainda que, como alguns salientam, estas atividades sejam adequadas às situações dos beneficiários e transferíveis para o mercado de trabalho principal. Enfim, mesmo que as empresas sociais possam ter efeitos positivos sobre a sociedade e os beneficiários empregando-os em verdadeiras condições produtivas, elas exercem uma ação sobre os efeitos dos processos de exclusão, e não sobre as causas. Não têm impacte direto sobre a situação económica ou sobre os mecanismos podendo estar na origem de exclusões ou de discriminações de todo o tipo (Badan, Bonvin \& Moachon, 2007). Todavia, como referencia Dunand (2010), contentar-se com este papel "paliativo" seria dar razão aqueles que pensam que as empresas sociais representam uma nova maneira de gerir os pobres, permitindo à atual 
economia de exclusão prosseguir as suas atividades tranquilamente. E acrescenta que a um trabalho de curto prazo de ajuda à inserção num mercado de emprego, os profissionais das empresas sociais deveriam associar um envolvimento a longo prazo para uma economia mais social, mais solidária e respeitadora dos equilíbrios ecológicos. Espera-se que aspirando a uma economia mais social e solidária, as empresas sociais representem uma melhor solução do que a ajuda social à exclusão. Com efeito, a inserção no mercado de trabalho primário tornou-se, para numerosas pessoas, uma exigência excessiva, enquanto uma ocupação (permanente) num atelier protegido não as estimula suficientemente (Adam, 2010).

\section{Que desafios para a intervenção em Serviço Social?}

O paradigma da inserção, incluindo a sua tradução nas empresas sociais, aparece pois como um elemento catalizador das mutações do trabalho social em geral, e do Serviço Social em particular. Estas mutações dizem respeito não somente aos públicos acompanhados, mas também aos próprios profissionais, questionando assim as suas identidades, funções e práticas profissionais. Deste modo a intervenção em Serviço Social deve superar diversos desafios.

A construção e o reconhecimento de uma legitimidade do serviço social para intervir no campo da inserção constitui sem dúvida um dos maiores desafios. A questão da legitimidade do Serviço Social parece particularmente acentuada do ponto de vista das dúvidas quanto à eficácia da sua ação. Ora estas dúvidas estão exacerbadas, precisamente, pelo importante desenvolvimento da inserção cuja eficácia dos dispositivos e das medidas mobilizadas, tendo em vista os resultados efetivamente obtidos, parece no mínimo discutível. Como salienta Knüsel a este respeito, "a busca de reinserção dos excluídos do mercado económico situa-se no limite dos campos do social e do económico. Várias questões se colocam desde logo quanto à legitimidade do trabalho social sobre este território" (citado por Soulet, 1997, pp. 300-301).

Os profissionais da inserção, em particular no contexto das empresas sociais, agem pois entre "lógicas de ação diferentes: o económico, o político e 
o social” (Hatzfeld, 1998, pp. 165-183). A articulação destas três lógicas cria espaços para novas ou renovadas práticas, "fundadas sobre competências cruzadas, sobre o conhecimento das capacidades e dos limites de cada um" (Hatzfeld, 1998, p. 3). Nesta ótica, a construção de uma "legitimidade de competência, fundada sobre um conjunto de conhecimentos teóricos e práticos, e de capacidades relacionais permitindo caracterizar uma situação e formular proposições adaptadas" (Hatzfeld, 1998, pp. 107-118) representa uma prioridade para o serviço social, pelo menos no contexto suíço.

Com efeito, a competência, ao mesmo tempo como "construção social", questionando nomeadamente os processos de qualificação, e como "construção individual" na sua concretização quotidiana, representa um elemento central em termos de desenvolvimento da legitimidade. No campo da inserção socioprofissional, pensamos que esta legitimidade se joga na interação e na articulação de (pelo menos) três níveis distintos de competências: as competências mobilizadas concretamente pelos profissionais (em ato), as esperadas pelos empregadores e as competências "construídas" pelos dispositivos de formação. Dito de outra forma, da coerência ou do afastamento entre as competências em ato, as competências em construção e as procuradas, dependerá a (não) legitimidade dos trabalhadores sociais e das suas intervenções no campo da inserção. Quanto mais esta coerência pareça presente e sólida, mais a legitimidade em questão aparecerá como defensável e indiscutível.

Nesta perspetiva, a legitimidade do Serviço Social para intervir no campo da inserção coloca diretamente a questão da sua própria qualificação. Assim, é a articulação entre a lógica da formação (nomeadamente teórica) e a da competência que se joga aqui. Nesta ótica, pensamos que é conveniente ultrapassar uma certa oposição estéril que parece existir entre estes dois pólos, e passar assim de uma posição de escolha entre competência OU formação, para uma conceção que considera ao mesmo tempo a formação $\mathrm{E}$ a competência. Trata-se de um desafio colocado não somente ao Serviço Social - na sua capacidade para intervir - mas também, e talvez sobretudo, às instâncias de formação - na sua capacidade para conceber e inovar nas respostas a construir em termos de intervenção - e, enfim, ao mundo do trabalho - na sua capacidade para negociar o mandato recebido dos financiadores e para definir as expectativas e necessidades que dele decorrem. 
Convém destacar, a este respeito, as tentativas recentes visando articular estes diferentes níveis no contexto da Suíça francófona. Pensámos em primeiro lugar num módulo de aprofundamento (15 ECTS) inscrito no programa de Bacharelato em Trabalho Social organizado pela HES-SO Valais e apelidado: Inserção profissional: que métodos e que instrumentos para a intervenção? Muitos assistentes sociais frequentaram este módulo após a sua criação em 2004. Pensámos de seguida em ofertas de formação contínua no campo da inserção a começar em 2012, sob o impulso conjunto das escolas de gestão e de trabalho social, bem como de meios profissionais como o Conselho Francófono da Inserção pelo Económico (Conseil Romand de l'Insertion par l'Economique, CRIEC) e a Associação dos Organizadores das Medidas do Mercado do Trabalho na Suíça (Association des Organisateurs des Mesures du Marché du Travail en Suisse, AOMAS).

Esta colaboração entre os mundos da formação e do terreno, deveria permitir gerir melhor a articulação das esferas económica e social, outro desafio de peso para as práticas profissionais no campo da inserção, e ainda mais no contexto das empresas sociais. E aí também pensamos que é preciso conceber a intervenção não opondo os dois paradigmas (um OU outro), mas sobretudo fazê-los interagir enquanto parceiros de igual importância ( $u m E$ o outro). Não se trata de colocar o social ao serviço do económico, ou o inverso, nem da instrumentalização de um pelo outro, e ainda menos de "vender a alma ao diabo", mas sobretudo de conjugar os dois no interesse "supremo" que deveria ser a inserção do beneficiário. Isto exige aos dois pelo menos aceitar dar um passo em direção ao outro, a fim de compreender as lógicas, os constrangimentos e as possibilidades de ação. É também aí que reside sem dúvida o sentido que o Serviço Social pode ao mesmo tempo dar e apropriar da sua intervenção no campo da inserção. Eis dois exemplos para ilustrar e concluir o nosso argumento ${ }^{30}$.

30 Não nos detemos aqui sobre as funções "clássicas» do serviço social, todavia presentes e importantes neste campo de intervenção, como a de especialista dos apoios sociais e da sua coordenação em problemáticas (sempre mais) complexas, a de expert na gestão administrativa dos dossiers pelos quais é responsável, ou ainda de seguimento e suporte dos beneficiários. Não exploramos também o case management e as suas modalidades de intervenção que parecem cada vez mais atrair a atenção dos profissionais de inserção. 
Primeiramente, agindo no "ponto de encontro entre as pessoas e o seu ambiente" (PEC06 Bacharelato em Trabalho Social, Capítulo 2.2.3. A orientação "Serviço Social”, 2006), o Serviço Social parece bem colocado para posicionar uma análise crítica sobre as oportunidades e os riscos ligados ao paradigma da inserção, bem como dos dispositivos que dele decorrem. Concretamente deveria estar em posição de fazer o contrapeso às tendências sobrerresponsabilizantes, moralizadoras, e até por vezes culpabilizantes das políticas ativas de inserção, e não contentar-se em ser o simples executante. Trata-se nomeadamente de recordar que a inserção está longe de ser apenas uma questão individual, mas uma problemática bem mais larga e complexa. Não basta querer estar inserido para o conseguir, é preciso que o contexto socioeconómico o permita! Trata-se também, em consequência, de «despsicologizar» as dificuldades associadas aos processos de inserção que não poderiam ser imputadas unicamente aos indivíduos (Dubet citado por Castra, 2003). Assim, para ultrapassar esta "norma de internalidade", o acompanhamento no campo da inserção numa empresa social, deve centrar-se não somente sobre os indivíduos e as dificuldades concretas que vivenciam nas situações reais de trabalho, mas também no seu contexto, e nomeadamente sobre a própria empresa e a sua gestão do pessoal, desde o recrutamento até ao seu enquadramento fixo e estabilizado. É o que propõe Castra na sua metodologia de "Intervenção sobre a oferta e a procura IOD 31 " (Castra, 2003; Castra \& Vals, 2008) que deixa antever perspetivas interessantes para o Serviço Social. Nesta ótica, as empresas sociais, com a sua preocupação de conjugar as dimensões social e económica, e até política, emergem como contextos propícios para este tipo de intervenção.

O segundo exemplo de oportunidade a aproveitar para o Serviço Social no campo da inserção é a defesa e a promoção dos "princípios dos direitos do homem e da justiça social [como] fundamentais na profissão" (PEC06 Bacharelato em Trabalho Social, Capítulo 2.2.3. A orientação "Serviço Social", 2006). Com efeito, recusando-se a "psicologizar o desemprego ou a criminalizar todos os comportamentos que não estejam conformes com as normas", o

31 IOD-Intervention sur l'Offre et la Demande. 
Serviço Social, com outros trabalhadores sociais, tem um papel fundamental a desempenhar na reabilitação "dos sistemas de pertenças e de proteções coletivas", enfraquecidas pelas "dinâmicas de individualização" já evocadas (Castel, 2009, p. 243). Neste sentido, convém lembrar que as intervenções sociais têm um "interesse" não somente para o indivíduo precarizado, desinserido, excluído, mas também para a sociedade no seu conjunto e a sua coesão. Por outras palavras, reinscrever os indíviduos no coletivo é também e sobretudo reforçar a coesão social. Assim, "o Serviço Social contribui também para a produção mais lata do que alguns concetualizam com o termo de elo social" (Tronche, Chauvière, Bouquet \& Ladsous, cité par Chauvière \& Tronche, 2002, p. 128).

Assegurando isto, o Serviço Social pode então reforçar o utente no seu estatuto de cidadão, tendo é certo deveres (ativação, contraprestação, etc.) mas também direitos fundamentais tais como a proteção e a participação social. $O$ assistente social pode assim participar ativamente na restauração da "cidadania social" do indivíduo, "com a condição de não esquecer que este interlocutor não é simplesmente um cliente com o qual negoceia, troca por troca, no âmbito de uma relação mercantil. É também um utente de um serviço público que tem direitos como cidadão" (Castel, 2009, pp. 245-247). E aqui também as empresas sociais de inserção, apesar dos limites e dos constrangimentos aos quais devem fazer face, deixam antever perspetivas em termos de participação, de justiça e de cidadania social. O futuro mostrará a sorte reservada a estas perspetivas.

\section{Bibliografia}

Adam, S. M. (2009). Les entreprises sociales entre désir et réalité. Panorama. N6/2009. Pp. 6-7. Antonin-Tattini, V. \& Bruttin, M-D (2009). Entreprises sociales d'insertion en Suisse: le revers de la dépendance aux dispositifs publics d'insertion. In: Viviane Guerdan et al. (éds). Berne: Peter Lang, pp. 119-129.

Astier, I. (2007). Les nouvelles règles du social. Paris: PUF.

Autès, M. (1999. Réédité en 2004). Les paradoxes du travail social. Paris: Dunod.

Badan, Ph., Bonvin, J.M. \& Moachon, E. (2004). Le rôle des acteurs locaux dans les nouvelles politiques de l'emploi. Revue suisse de sociologie, Vol. 30 (3), 381-396 
Badan, Ph., Bonvin, J.M. \& Moachon, E. (2007). Les politiques atives de l'emploi au service de la réduction des inégalités? In: Batifoulier, Philippe et al. (éds). Approches institutionnalistes des inégalités en économie sociale. Paris: L’Harmattan, pp. 335-348.

Bonoli, G. (2008). «Réorienter les régimes sociaux vers la réinsertion professionnelle». Working paper. Lausanne: IDHEAP.

Bregeon, Ph. (2008). A quoi servent les professionnels de l'insertion? L'exemple des intervenants sociaux en Centres d'Hébergement et de Réinsertion Sociale, en Missions Locales et dans l'Insertion par l'Activité Economique. Paris: L'Harmattan.

Cantel, F. \& Genard, J.-L. (2007). Action publique et subjectivité. Paris: LGDJ, Collection Droit et Société.

Castel, R. (1995). Les métamorphoses de la question sociale. Une chronique du salariat. Paris: Fayard.

Castel, R. (2003). L'insécurité sociale. Qu'est-ce qu'être protégé? Paris: Seuil.

Castel, R. (2009). La montée des incertitudes. Travail, protections, statut de l'individu. Paris: Seuil.

Castra, D. (2003, 1ère éd). L'insertion professionnelle des publics précaires. Paris: PUF.

Castra, D. \& Valls F. (2007, réimpression en 2008). L'insertion malgré tout. L'Intervention sur l'Offre et la Demande. 25 ans d'expérience. Toulouse: Octares éditions.

Chauvière, M \& Tronche, D. (dir). (2002). Qualifier le travail social. Dynamique professionnelle et qualité de service. Paris: Dunod.

Chopart, J-N. (dir.). (2000). Les mutations du travail social. Dynamiques d'un champ professionnel. Paris: Dunod.

De Jonckeere, C., Mezzena, S. \& Molnarfi, C. (2008). Les entreprises sociales d'insertion par l'économique. Des politiques, des pratiques, des personnes et des paradoxes. Genève: ies éditions.

Dunand, Ch. (2004). Les entreprises d'insertion en Suisse romande: Des expériences nombreuses, un dispositif complexe dans un système politique fédéraliste décentralisé. Papier présenté lors de la première rencontre internationale d'entreprises d'insertion. Dunand, Ch. (2010). Les entreprises sociales face au chômage et à la pauvreté. Actualité Sociale. $\mathrm{N}^{\circ} 25$. Mars-Avril.

Dunand, Ch. \& Dupasquier, A.L. (2006). Travailler pour s'insérer. Des réponses atives face au chômage et à l'exclusion. Genève: ies éditions.

Freynet, M.F. (2003, $4^{\mathrm{e}}$ éd.). Les médiations du travail social. Contre l'exclusion, (re)reconstruire les liens. Lyon: Chronique sociale.

Guichard, J. \& Huteau, M. (dir.). (2007). Orientation et insertion professionnelle. 75 concepts clés. Paris: Dunod.

Hatzfeld, H. (1998). Construire de nouvelles légitimités en travail social. Paris: Dunod.

Laville, J.-L. (dir., 1994). L'économie solidaire: une perspetive internationale. Paris: Desclée de Brouwer.

Programme d'Etudes Cadre Bachelor 2006. Filière de formation en travail social. (2006). HES-SO: Adopté par le Comité Directeur de la HES-SO le 8 septembre 2006.

Repère Social. (2004). L'aide sociale sous condition. Revue d'information sociale. $\mathrm{N}^{\circ} 61$. Octobre. (pp. 5-13).

Rosanvallon, P. (1981). La crise de l'Etat-providence. Paris: Seuil.

Rosanvallon, P. (1995). La nouvelle question sociale. Repenser l'Etat-providence. Paris: Seuil. 
Soulet, M-H. (éd.). (1997). Les transformations des métiers du social. Fribourg: Editions Universitaires Fribourg Suisse.

Soulet, M-H. (éd.). (1999). Le travail, nouvelle question sociale. Fribourg: Editions Universitaires Fribourg Suisse,

Soulet, M-H. (éd). (2006). Chômage et solidarité: les nouvelles inégalités. Fribourg: Academic Press Fribourg, Editions Saint-Paul, (pp. 155-178).

Soulet, M-H. (2008). Les paradoxes des politiques de réinsertion. In: http://www.reiso.org/revue. Revue d'information sociale indépendante (consulté en septembre 2011).

Supiot, A. (2002). La contractualisation de la société. In: La société et les relations sociales / Université de tous les savoirs. Sous la dir. d'Yves Michaud. Paris: Odile Jacob, pp. 57 - 71).

Tecklenburg, U. (2006). Les entreprises sociales. Lucerne: Caritas. Exposé de la journée thématique "Fonder des entreprises sociales", 25 septembre 2006.

Vrancken, D. (2010). Le nouvel Ordre protectionnel. De la protection sociale à la sollicitude publique. Lyon: Parangon/VS. Collection situations \& critiques.

Vrancken, D. \& Thomsin, L. (dir.). (2008). Le social à l'épreuve des parcours de vie. Louvain-La-Neuve: Academia Bruylant. 
(Página deixada propositadamente em branco) 